\title{
COLOUR DOPPLER VELOCIMETRY OF THE ARTERIAL VASCULATURE OF THE OPTIC NERVE HEAD AND ORBIT
}

\author{
TOM H. WILLIAMSON ${ }^{1}$, GRANT M. BAXTER ${ }^{2}$ and GORDON N. DUTTON ${ }^{1}$ \\ Glasgow
}

\begin{abstract}
SUMMARY
Blood flow in the orbital vasculature can be investigated by colour Doppler velocimetry which allows simultaneous imaging of B-scan and Doppler ultrasound. In this paper we review the results of our recent studies on the arterial vasculature of the orbit and optic nerve head. A control study is described in which reliable measurements were obtained from the ophthalmic artery at the orbital apex, the medial orbit, and the complex of the central retinal artery and posterior ciliary arteries. Patients with occlusion of the central retinal artery and posterior ciliary arteries were examined. The results indicate that readings at the optic nerve head primarily represent blood flow in the central retinal artery. A study of the effects of posture on velocimetry demonstrated no change in the measurements obtained. Finally, topical timolol $0.5 \%$ was found to reduce the resistive indices of flow in the central retinal artery.
\end{abstract}

The complexity of blood flow in the eye and orbit has resulted in the development of many methods of assessment, but none has satisfied all requirements. Significant artefact may be engendered by invasive measurements, which also necessitate recourse to animal models. ${ }^{1-4}$ Errors of measurement of blood flow may occur in other methods because of the use of pharmacological agents such as mydriatics or because of the requirement for the application of pressure on the globe..$^{5-9}$

Colour Doppler imaging facilitates the examination of blood velocity in sites of complex vasculature by providing simultaneous Doppler and B-scan ultrasound images on a VDU screen. Areas of blood flow are indicated on the screen by coloured pixels whilst the simultaneously presented B-scan provides an image of the anatomy of the tissue. A Doppler sample gate can then be directed to a site of blood flow and pulsed ultrasound employed to obtain Doppler measurements of the velocity of blood flow in the

From: ${ }^{1}$ Tennent Institute of Ophthalmology and ${ }^{2}$ Department of Radiology, Western Infirmary, Glasgow, UK.

Correspondence to: Tom H. Williamson, FRCS, FCOphth, Tennent Institute of Ophthalmology, Western Infirmary, Glasgow G11 6NT, UK. vessel. This provides a non-invasive examination technique which has been used in the assessment of a wide range of conditions. The utility of this equipment for investigating blood flow in the orbit has only recently been described. ${ }^{10-12}$

It is essential that careful evaluation of colour Doppler ultrasound is carried out before it is widely used in clinical practice. In this paper we describe our recent work in this area and review the results of our published studies. Firstly, an examination of a control population was performed to determine positions in the orbit from which measurements can be reliably reproduced and to determine the normal range of recordings for these sites. ${ }^{12}$ Our findings are described along with additional subsequent control data. Secondly, an examination was performed to determine the degree of elevation of intraocular pressure (IOP) produced by the application of the ultrasound transducer onto the globe. Thirdly, we investigated the pattern of blood flow recordings obtained at the optic nerve head by examining groups of patients with either acute or longstanding central retinal artery occlusion or posterior ciliary artery occlusion. ${ }^{13}$ Finally, a study of the effects of changes in posture and topical beta blockade is reviewed. ${ }^{12}$

\section{PATIENTS AND METHODS}

\section{Colour Doppler Ultrasound}

An Acuson 128 with a $7.5 \mathrm{MHz}$ probe was used to obtain velocimetry measurements. The eye and orbit were imaged with the patient supine, eyes closed and directing the gaze towards the ceiling. Contact jelly was applied to the closed upper lid and the scan was performed. An attempt was made to minimise the pressure applied to the globe during the examination by resting the examiner's hand on the orbital margin before placing the transducer onto the closed lid.

Areas of blood flow were detected by the production of colour on the VDU screen and then a Doppler gate of $1.5 \times 1.5 \mathrm{~mm}$ was directed towards the site and pulsed Doppler ultrasound used to obtain velocimetry readings. 
A reading was taken only when three consecutive pulse waveforms were obtainable from a blood vessel. Maximal (systolic) and minimal (diastolic) velocities of blood flow were determined by averaging the readings from three waveforms and the resistive index was calculated according to the formula:

Resistive index $=\frac{\text { Maximal velocity }- \text { minimal velocity }}{\text { Maximal velocity }}$

Informed consent was obtained from all volunteers and patients before examination.

\section{Controls}

One orbit (randomly allocated to right or left) of each of 30 healthy volunteers was examined to determine the sites from which arterial velocimetry measurements could be taken. The values obtained were used to produce control data for further studies.

\section{Determination of the Intraocular Pressure Rise Produced by Ultrasound Examination}

In order to determine the pressure being applied to the globe during the examination an experimental model was designed to allow simultaneous IOP measurements and B-scan ultrasound. A fresh pig's eye was supported in the orbital cavity of a human skull with an isosonic material and covered with a thin sheet of latex rubber. Four ultrasonographers were then asked to perform five B-scan ultrasound examinations of the globe and were asked to image the lens and posterior pole of the eye. A pressure transducer (Statham Strain Gauge Pressure Transducer) had been inserted into the anterior chamber of the pig's eye to provide a continuous reading of the IOP during each examination (Devices Instruments Ltd). The ultrasonographers were masked from the results of the IOP measurements during the imaging.

\section{Assessment of Blood Flow at the Optic Nerve Head}

The flow of blood within the multiple blood vessels at the optic nerve head produces a complex colour Doppler pattern. In order to elucidate the contribution of the central retinal artery and the posterior ciliary arterial supply to this pattern we investigated 14 patients with occlusive pathology at these sites. Eight of these patients were examined within 24 hours of loss of vision (4 with central retinal artery occlusion and 4 with anterior ischaemic optic neuropathy). These patients were again examined after 1 week. Six patients were examined at least 3 weeks after occlusion ( 3 with central retinal artery occlusion and 3 with anterior ischaemic optic neuropathy). Fluorescein angiographic photographs were interpreted by an observer in a masked fashion in order to corroborate the clinical diagnosis.

\section{Effects of Posture}

Twenty volunteers were examined for the effects of posture on the velocimetric readings from the orbital arteries by examination in supine, sitting and standing positions.
After each change of posture a rest period of 5 minutes was employed before measurements were obtained. Blood pressure and pulse were monitored using a digital sphygmomanometer.

\section{Effects of Timolol $0.5 \%$}

Ten healthy volunteers applied topical timolol $0.5 \%$ to one eye (chosen at random) and were examined before instillation and at 2 hours after instillation. The drug was administered twice daily for a further 3 days and the ultrasound repeated. IOP, systemic blood pressure and pulse were also measured on each occasion.

\section{RESULTS}

\section{Controls}

The control group (age range 20-60 years, mean 33.7 years) comprised 10 females and 20 males. Three sites, which we have designated positions 1,2 and 3, provided velocimetry measurements. Position 1 , comprising a single artery at the orbital apex, was detectable in 24 of the 30 controls. Position 2 represented a single artery which ran along the medial orbital wall and was detected in all control patients. These positions give velocimetry readings which are statistically similar. Position 3 at the optic nerve head provided a smaller pulse reading which was obtained from colour signals in the centre of and surrounding the optic nerve (Fig. $1 a$ ). Readings were detectable from all patients at this site. Table I shows the mean maximum velocimetry results from these positions and Table II shows the resistive indices.

\section{Determination of the Intraocular Pressure (IOP) Rise Produced by Ultrasound Examination}

The mean IOP rises during the five examinations by the four ultrasonographers are shown in Fig. 2. Considerable variation was shown between the examiners (Table III), interobserver comparisons all being significantly different to $p<0.001$. Ultrasonographer 2 induced the lowest IOP rises and has performed all of the colour Doppler imaging in the studies of control populations and disease processes described in this paper.

\section{Arterial Occlusion}

In 3 patients with acute central retinal artery occlusion no blood flow was detectable in the central optic nerve at position 3. Peripapillary colour indices of flow were present (Fig. 1b). Although occasional pulse velocimetry readings were obtainable from these sites no reproducible measurements (three consecutive pulse waveforms) could be obtained. Fluorescein angiography in these patients confirmed the diagnosis and revealed an intact posterior ciliary circulation as evidenced by normal choroidal and optic nerve head perfusion (Table IV).

Doppler studies in 3 patients with acute anterior ischaemic optic neuropathy showed no detectable peripapillary colour indices but did show evidence of a central vessel at the optic nerve head (Fig. 1c). Velocimetry 


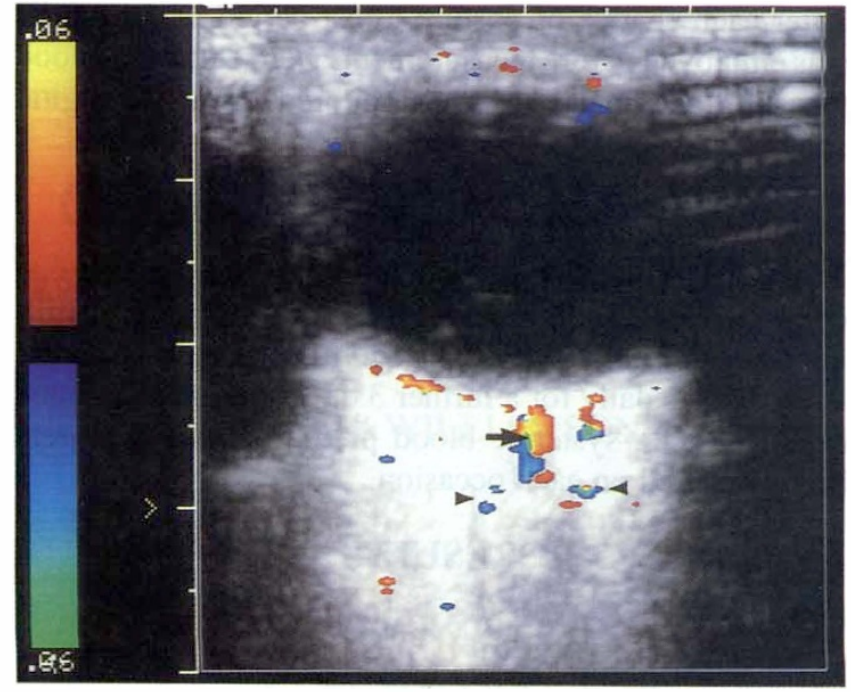

Fig. 1a

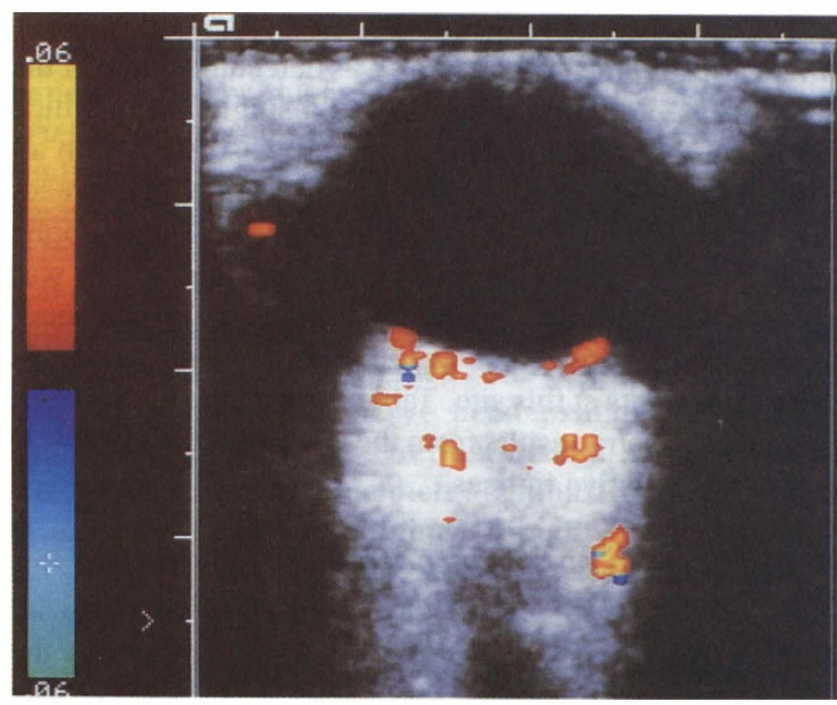

Fig. $1 b$

measurements were obtained from the optic nerve head (position 3) in all of these patients. Fluorescein angiographic evidence of normal dye transit times confirmed the presence of normal central retinal artery perfusion in these patients. Delayed choroidal filling and absent optic nerve head perfusion provided evidence for reduced posterior ciliary artery circulation (Table IV).

The Doppler results at the optic nerve head (position 3) were normal in all 6 patients whose vascular occlusion had occurred more than 3 weeks earlier. Normal recordings were also obtained from 1 patient with acute central retinal

Table I. The maximum (systolic) velocities recorded for positions 1, 2 and 3

\begin{tabular}{lcr}
\hline Position & $\begin{array}{c}\text { Mean maximal velocity (SD) } \\
(\mathrm{m} / \mathrm{s})\end{array}$ & $\begin{array}{c}\text { Range } \\
(\mathrm{m} / \mathrm{s})\end{array}$ \\
\hline 1 & $0.272(0.192)$ & $0.074-0.83$ \\
2 & $0.37(0.122)$ & $0.11-0.65$ \\
3 & $0.097(0.026)$ & $0.056-0.17$ \\
\hline
\end{tabular}

Readings from positions 1 and 2 are not significantly different whereas those from position 3 are significantly lower than those from positions 1 and $2(p<0.0001)$.



Fig. 1c

Fig. 1. Colour Doppler ultrasound recordings. (a) Normal recording at position 3 in the orbit showing the central retinal artery (arrow) and posterior ciliary arteries (arrowheads). (b) Recording from the optic nerve head in a patient with central retinal artery occlusion. Note the complete absence of the recording from the central retinal artery although peripapillary flow persists. (c) Recording from the optic nerve head in a patient with acute anterior ischaemic optic neuropathy. The centrally placed artery remains patent while there is absence of surrounding peripapillary flow.

artery occlusion and one with acute anterior ischaemic optic neuropathy. Fluorescein angiography demonstrated that perfusion of the retinal and posterior ciliary arterial circulations had been restored in these patients.

\section{Effects of Posture}

No effect of a change in posture was seen in velocimetry readings at any of the sites measured, despite rises in diastolic blood pressure and pulse when changing from a supine or sitting position to standing (Table V), whilst rises in diastolic blood pressure and pulse rate were significant at $p<0.01$ and $p<0.05$, respectively. This is

Table II. Mean resistive indices for positions 1, 2 and 3

\begin{tabular}{lcc}
\hline Position & Mean resistive index (SD) & Range \\
\hline 1 & $0.76(0.096)$ & $0.557-0.966$ \\
2 & $0.77(0.087)$ & $0.566-0.892$ \\
3 & $0.68(0.073)$ & $0.575-0.811$ \\
\hline
\end{tabular}

Readings from position 3 are significantly lower than those from positions 1 and 2 ( $p<0.005$ and $p<0.0001$ respectively). 

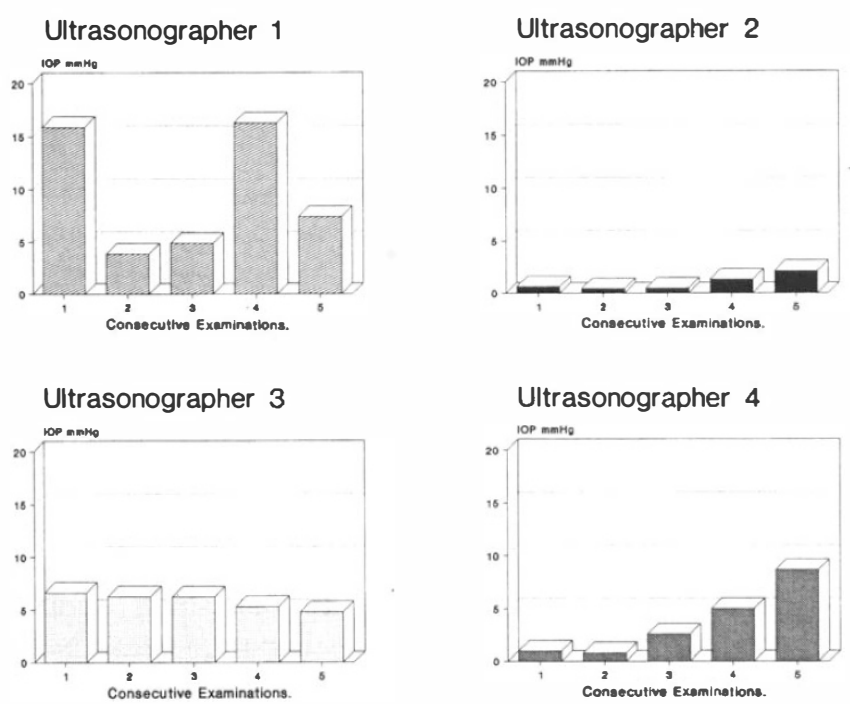

Fig. 2. The mean IOP rises in a pig's eye for each of five $B$-scan ultrasound examinations by four ultrasonographers.

Table III. The mean IOP rise and range of IOP rises induced in a pig's eye during five consecutive B-scan ultrasonographies by four ultrasonographers

\begin{tabular}{lcc}
\hline Ultrasonographer & Mean IOP rise $(\mathrm{mmHg})$ & Range $(\mathrm{mmHg})$ \\
\hline 1 & 10.2 & $0-24$ \\
2 & 1.4 & $0-8$ \\
3 & 6.0 & $4-11$ \\
4 & 3.3 & $0-11$ \\
\hline
\end{tabular}

Considerable variation between the operators is apparent.

indicative of the presence of autoregulation in the blood vessels of the orbit.

\section{Effects of Timolol $0.5 \%$}

Topical timolol $0.5 \%$ induced a fall in resistive index in the central retinal artery in both the treated eye and the fellow eye (significant to $p<0.05$ and $p<0.01$ respectively, Table VI). No effect was seen on velocimetry readings in the ophthalmic artery (positions 1 and 2). At 2 hours and 3 days there was a persistent reduction in IOP in the treated eyes only ( $p<0.01$ for both times). Blood pressure and pulse were unaffected. Table VII shows the changes in estimated perfusion pressure of the eye, calculated from the formula: ${ }^{14}$

Perfusion pressure $=2 / 3$ mean brachial BP - IOP where BP is blood pressure.

\section{DISCUSSION}

In our initial study we identified three sites in the orbit from which repeatable velocimetry measurements could be taken. These probably represent the ophthalmic artery in the posterior and medial orbit (positions 1 and 2 respectively) and the posterior ciliary and central retinal arteries at the optic nerve head (position 3). Doppler examination of the ophthalmic artery provided pulse readings and velocimetry measurements which were significantly larger than those from the optic nerve head region $(p<0.01$ and $p$ $<0.001$ for positions 1 and 2 respectively).

Velocimetry results from position 1 showed a wider range than those from position 2 . In 6 of the 30 control subjects consistent readings from position 1 could not be obtained. The ophthalmic artery is variable in its course in the posterior orbit (position 1), passing either above or below the optic nerve head, ${ }^{15}$ and may have a dual supply from the internal carotid and middle meningeal artery, which anastomoses distal to this site in the posterior orbit. ${ }^{15}$ We believe that Doppler measurements of the ophthalmic artery are best taken from position 2 where the antero-posterior orientation of the artery can be exploited. It may be argued, however, that readings from position 2 may be of reduced relevance to the study of ocular blood flow because the posterior ciliary and central retinal arteries have already branched off the ophthalmic artery before it reaches the medial orbit. The antero-posterior vector of the central retinal artery within the optic nerve head (position 3) is also advantageous to the measurement of Doppler indices which otherwise would require corrections for oblique vectors.

External pressure from the ultrasound transducer may potentially result in an increase in IOP during the examination. It is important during Doppler imaging to minimise this external pressure so as to reduce any potential effect on blood flow. We have determined that there is a considerable variation in the IOP rise induced by different ultrasonographers. With the exception of one operator, the elevation in IOP was limited to a maximum of $11 \mathrm{mmHg}$ and the mean rises were small. Previous animal experimentation has shown that the retinal blood flow remains stable during moderate rises in $\mathrm{IOP}^{16,17}$ and in humans Riva et al. (using laser Doppler velocimetry) have shown that blood velocity in the retinal circulation is effectively autoregulated up to IOPs of $42 \mathrm{mmHg} .{ }^{18}$ It would appear, therefore, that the small IOP rises produced during the ultrasound examination are unlikely to influence blood flow velocity measurements, but further study will be required in this area of investigation. Our experimental model could potentially be used to train ultrasonographers to minimise the IOP rises that are caused during imaging.

The contribution of the multiple arteries at site 3 to the velocimetry readings from this region could not be determined by our examination of healthy volunteers. Lieb et $a l$., who used a different colour Doppler system but who

Table IV. The results of fluorescein angiography of eyes with abnormal position 3 (optic nerve head) scans for patients with central retinal artery occlusion (CRAO) and anterior ischaemic optic neuropathy (AION)

\begin{tabular}{lclcc}
\hline Case & Diagnosis & Optic nerve & Tmvf (s) & $\begin{array}{c}\text { Choroid/ } \\
\text { retinal }\end{array}$ \\
\hline 1 & CRAO & Normal & 38.1 & 0.0 \\
2 & CRAO & Normal & 11.2 & 3.5 \\
3 & CRAO & Normal & 35.8 & 5.4 \\
4 & AION & No inferior fill & 6.5 & 0.0 \\
5 & AION & No inferior fill & 6.6 & -4.6 \\
6 & AION & No inferior fill delay & 8.2 & -6.8 \\
& & superiorly & \\
\hline
\end{tabular}

Results are shown of the masked assessment of optic nerve head perfusion, time to maximal venous filling of dye (Tmvf) and time to choroidal perfusion relative to the first appearance of dye in retinal arterioles (a negative result indicates choroidal filling after retinal arteriolar filling). 
Table V. The results of changes in posture on various parameters

\begin{tabular}{lcccllll}
\hline & \multicolumn{3}{c}{ Systemic } & & \multicolumn{3}{c}{ Ophthalmic artery } \\
\cline { 2 - 3 } & $\begin{array}{c}\text { Pulse } \\
\text { (beats/min) }\end{array}$ & $\begin{array}{c}\text { SBP } \\
(\mathrm{mmHg})\end{array}$ & $\begin{array}{c}\text { DBP } \\
(\mathrm{mmHg})\end{array}$ & $\begin{array}{l}\text { Max. } \\
(\mathrm{m} / \mathrm{s})\end{array}$ & $\begin{array}{c}\text { Min. } \\
(\mathrm{m} / \mathrm{s})\end{array}$ & RI \\
\hline Supine & 70.6 & 118.0 & 71.7 & & 0.337 & 0.075 & 0.77 \\
Sitting & 72.6 & 113.5 & 72.9 & & 0.300 & 0.057 & 0.81 \\
Standing & $78.6^{* *}$ & 114.0 & $79.8^{*}$ & & 0.273 & 0.055 & 0.79 \\
\hline
\end{tabular}

The results of changes in posture are shown for mean pulse rate and systemic systolic and diastolic blood pressures (SBP, DBP), with a significant rise in both pulse rate $\left({ }^{* *} p<0.01\right)$ and DBP $\left({ }^{*} p<0.05\right)$. Also shown are the results of mean maximum and minimum blood velocities (Max., Min.) and resistive indices (RI) in the ophthalmic artery at position 2 . There was a trend for a reduction in maximum velocity which was not significant.

also employed at $7.5 \mathrm{MHz}$ probe, claim to be able to examine blood flow in the central retinal artery and the temporal and nasal posterior ciliary arteries. It is noteworthy, however, that their range of maximal systolic velocities for the posterior ciliary arteries was large (1.4$22.7 \mathrm{~cm} / \mathrm{s}) .{ }^{11}$ We were able to provide only one reproducible measurement at the optic nerve region. Our study of patients with known occlusion of the vasculature at the optic nerve head has shown that with our technique and apparatus the posterior ciliary vasculature can be detected but does not allow reproducible velocimetry measurements. This is not surprising as these arteries are small, tortuous and variable in number. Our study shows that measurements obtained from the vasculature of the optic nerve head region are representative of the central retinal artery. This blood vessel is usually single, of uniform diameter and straightest just posterior to the optic nerve head where our measurements are taken. ${ }^{19}$ Colour Doppler imaging thus has the potential to investigate patients with presumed arterial occlusion at the optic nerve head without recourse to fluorescein angiography. It also has the advantage that the orbital vasculature can simultaneously be examined for evidence of such occlusive pathology as giant cell arteritis.

We have used colour Doppler ultrasound to examine the velocity of blood flow with changes in posture. Despite significant changes in blood pressure and pulse no changes were seen in maximum or minimum velocity or resistive index in the central retinal or ophthalmic arteries, suggesting that autoregulation of blood flow was present. To our knowledge this is the first description of this effect in the ophthalmic artery. In contrast, Canning and Restori using duplex Doppler scanning in an undisclosed number of subjects found that there was an increase in the diastolic blood velocity in the supine position. ${ }^{20}$

Table VI. The fall in mean resistive indices in the treated and fellow eye after the instillation of timolol $0.5 \%$

\begin{tabular}{|c|c|c|}
\hline & \multicolumn{2}{|c|}{ Resistive index (SD) } \\
\hline & Treated eye & Fellow eye \\
\hline Pre-treatment & $67.6(8.1)$ & $68.5(6.66)$ \\
\hline 2 hours treatment & $59.4(9.14)$ & $58.5(8.34)$ \\
\hline 3 days treatment & $58.8(7.56)$ & $57.3(7.17)$ \\
\hline
\end{tabular}

Results were significant to $p<0.05$ and $p<0.01$ respectively for both 2 hours and 3 days of treatment.
Table VII. The results of calculations of perfusion pressure of the eye treated with topical timolol $0.5 \%$ and the fellow eye

\begin{tabular}{lll}
\hline & \multicolumn{2}{c}{ Mean perfusion pressure (SD) $(\mathrm{mmHg})$} \\
\cline { 2 - 3 } & \multicolumn{1}{c}{ Treated eye } & Fellow eye \\
\hline Pre-treatment & $48.08(3.73)^{*}$ & $48.08(3.87)$ \\
2 hours treatment & $52.68(3.97)^{*}$ & $49.58(4.52)$ \\
3 days treatment & $50.30(5.72)$ & $47.40(4.91)$ \\
\hline
\end{tabular}

There is no change in perfusion pressure except for an increase 2 hours post-administration in the treated eye $\left({ }^{*} p<0.05\right)$.

The effects of beta blockade on blood flow to the eye and particularly the optic nerve head have been the subject of much inconclusive investigation. Using widely different techniques some authors have shown differing effects of topical timolol $0.5 \% .^{7,14,21-23}$ In our study, timolol reduced the resistive index (suggesting an increase in the velocity of blood flow) in the treated and the fellow eye. With evidence of a stable or elevated perfusion pressure, this increased velocity may be compensating for the vasoconstriction reportedly induced by topical beta blockade, ${ }^{24}$ thereby maintaining blood flow to the retina. The bilateral response indicates that the effect may result from systemic rather than local absorption of the drug.

The potential of colour Doppler ultrasound in the assessment and management of ophthalmic disorders is currently being realised. Further controlled studies are required, however, before it can be utilised as a routine clinical test. Even so, it has been used in the investigation of malignant melanoma, ${ }^{25}$ corticocavernous fistula ${ }^{26}$ and cases of carotid artery disease, ${ }^{27}$ orbital varix,${ }^{1,28}$ gazeinduced amaurosis fugax ${ }^{29}$ superior ophthalmic vein thrombosis, ${ }^{1,30}$ and persistent hyperplastic primary vitreous. ${ }^{31}$ The authors have used the technique to influence directly the management of a case of giant cell arteritis. ${ }^{32}$ In this patient colour Doppler ultrasound demonstrated absent orbital blood flow at a stage in the disease process when further visual loss occurred. This was despite apparently adequate control of the disease process according to conventional parameters. Colour Doppler ultrasound is a non-invasive test which has the advantage of providing objective measurements of the velocity of blood flow in the eye and orbit. We believe that the technique will allow us to investigate the behaviour of the many vascular disorders in the eye and orbit, particularly where serial measurements are required to monitor a disease process.

The help of Dr. David Keating is acknowledged in the IOP experiment.

Key words: Artery occlusion, Color Doppler, Colour Doppler, Eye, Intraocular pressure, Optic nerve, Orbit, Posture, Timolol.

\section{REFERENCES}

1. Geijer C, Bill A. Effects of raised intraocular pressure on retinal, prelaminar, laminar and retrolaminar optic nerve blood flow in monkeys. Invest Ophthalmol Vis Sci 1979;18: $1030-42$.

2. Capriolo J, Miller JM. Measurement of optic nerve blood flow with iodoantipyrine: limitations caused by diffusion from the choroid. Exp Eye Res 1988;47:641-52.

3. Alm A, Bill A. Ocular and optic nerve blood flow at normal 
and increased intra-ocular pressures in monkeys (Macaca irus): a study with radioactive labelled microspheres including flow determination in brain and some other tissues. Exp Eye Res 1973;15:15-29.

4. Khoobehi B, Peyman GA, Niesman MR, Oncel M. Measurement of retinal blood velocity and flow rate in primates using a liposome dye system. Ophthalmology 1989; 96:905-12.

5. Gee W, Oller DW, Homer LP, Bailey RL. Simultaneous bilateral determination of the systolic pressure of the ophthalmic arteries by ocular pneumoplethysmography. Invest Ophthalmol Vis Sci 1977;16:86-9.

6. Ulrich WP, Ulrich Ch. Oculo-oscillo-dynamography: a diagnostic procedure for recording ocular pulses and measuring retinal and ciliary artery blood pressures. Ophthalmol Res 1985;17:308-12.

7. Grunwald JE, Furubayashi C. Effect of topical timolol on the ophthalmic artery blood pressure. Invest Ophthalmol Vis Sci 1989;30:1095-100.

8. Riva CE, Grunwald GE, Sinclair SH, Petrig BL. Blood velocity and volumetric flow rate in human retinal vessels. Invest Ophthalmol Vis Sci 1985;26:1124-32.

9. Sinclair SH, Azar-Cavanagh M, Soper KA, Tuma RF, Mayrovitz HN. Investigation of the source of blue field entoptic phenomenon. Invest Ophthalmol Vis Sci 1989;30:668-73.

10. Erickson SJ, Hendrix LE, Massaro BM, Harris GJ, Lewandowski MF, Foley WD, Lawson TL. Colour Doppler flow imaging of the normal and abnormal orbit. Radiology 1989; 173:511-6.

11. Lieb WE, Cohen SM, Merton DA, Sheilds JA, Mitchell DG, Goldberg BB. Colour Doppler imaging of the eye and orbit, technique and normal anatomy. Arch Ophthalmol 1991;109: 527-31.

12. Baxter GM, Williamson TH, MacKillop G, Dutton GN. Colour Doppler ultrasound of the orbit, the effects of posture and topical timolol. Invest Ophthalmol Vis Sci 1992;33: 604-10.

13. Williamson TH, Baxter GM, Dutton GN. Colour Doppler ultrasound of the optic nerve head in arterial occlusion. Ophthalmology (in press).

14. Grunwald JE. Effect of topical timolol on the human retinal circulation. Invest Ophthalmol Vis Sci 1986;27:1713-19.

15. Singh S, Dass R. The central artery of the retina. I. Origin and course. Br J Ophthalmol 1960;44:193-212.

16. Geijer C, Bill A. Effects of raised intraocular pressure on retinal, prelaminar optic nerve blood flow on monkeys. Invest Ophthalmol Vis Sci 1979;18:1030-42.

17. Alm A, Bill A. Ocular and optic nerve blood flow at normal and increased intraocular pressures in monkeys (Macaca irus): a study with radioactively labelled microspheres including flow determinations in brain and some other tissues. Exp Eye Res 1973;15:15-29.

18. Riva CE, Grunwald JE, Petrig BL. Autoregulation of human retinal blood flow. An investigation with laser Doppler velocimetry. Invest Ophthalmol Vis Sci 1986;27:1706-12.

19. Hayreh SS. The ophthalmic artery. III. Branches. Br J Ophthalmol 1962;46:212-47.

20. Canning CR, Restori M. Doppler ultrasound studies of the ophthalmic artery. Eye 1988;2:92-5.

21. Yan HY, Chiou GCY. Effects of l-timolol, d-timolol, haloperidol and domperidone on rabbit retinal blood flow measured with laser Doppler method. Ophthalmic Res 1987;45:45-8.

22. Pullinat LE, Stodmeister R, Wimanns I, Metzner D. Effect of timolol on optic nerve head autoregulation. Ophthalmologica 1986;193:146-53.

23. Jay WM, Aziz MZ, Green K. Effect of topical epinephrine and timolol on ocular and optic nerve blood flow in phakic and aphakic rabbit eyes. Curr Eye Res 1984;3:1199-202.

24. Martin XD, Rabineau PA. Vasconstrictive effect of topical timolol on human retinal arteries. Graefes Arch Clin Exp Ophthalmol 1989;227:526-30.

25. Guthoff RF, Berger RW, Winkler P, Helmke K, Chumbley LC. Doppler ultrasonography of malignant melanomas of the uvea. Arch Ophthalmol 1991;109:537-41.

26. Flaharty PM, Lieb WE, Sergott RC, Bosley TM, Savino PJ. Colour Doppler imaging, a new non-invasive technique to diagnose and monitor carotid cavernous sinus fistulas. Arch Ophthalmol 1991;109:522-6.

27. Lieb WE, Flaharty PM, Sergott RC, Medlock RD, Brown GC, Mosley T, Savino PJ. Colour Doppler imaging provides accurate assessment of orbital blood flow in occlusive carotid artery disease. Ophthalmology 1991;98:548-52.

28. LiebWE, Merton DA, Sheilds JA, Cohen SC, Mitchell DD, Goldberg BB. Colour Doppler imaging in the demonstration of an orbital varix. Br J Ophthalmol 1990;74:305-8.

29. Knapp ME, Flaharty PM, Sergott RC, Savino PJ, Mazzoli RA, Flanagan JC. Gaze-induced amaurosis from the central retinal artery compression. Ophthalmology 1992;99: 238-40.

30. Flaharty PM, Phillips W, Sergott RC, Stefanyszyn M, Bosley T, Savino PJ, et al. Colour Doppler imaging of superior ophthalmic vein thrombosis. Arch Ophthalmol 1991;109: 582-3.

31. Wells RG, Miro P, Brummond R. Colour-flow Doppler sonography of persistent hyperplastic primary vitreous. J Ultrasound Med 1991;10:405-7.

32. Williamson TH, Baxter GM, Paul R, Dutton GN. Colour Doppler ultrasound in the management of a case of cranial arteritis. Br J Ophthalmol 1992;76:690-1. 